\title{
Being and becoming a university teacher
}

\author{
Wendy McMillan \& Natalie Gordon
}

To cite this article: Wendy McMillan \& Natalie Gordon (2017) Being and becoming a university teacher, Higher Education Research \& Development, 36:4, 777-790, DOI: 10.1080/07294360.2016.1236781

To link to this article: https://doi.org/10.1080/07294360.2016.1236781

曲 Published online: 30 Sep 2016.

Submit your article to this journal

Џll Article views: 922

Q View related articles $₫$

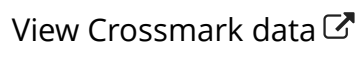

4 Citing articles: 5 View citing articles 지 


\title{
Being and becoming a university teacher
}

\author{
Wendy McMillan ${ }^{\text {at }}$ and Natalie Gordon ${ }^{\mathrm{b}}$ \\ ${ }^{\mathrm{a}}$ Faculty of Dentistry, University of the Western Cape, Cape Town, South Africa; ${ }^{\mathrm{b}}$ Department of Oral Hygiene, \\ Faculty of Dentistry, University of the Western Cape, Cape Town, South Africa
}

\begin{abstract}
This study examined how one academic framed the enablements and constraints to her project of being and becoming an academic. Complexity facilitated reflection in that it provided a visual representation of data, which was used to generate a concept map, which represented as equal all the component parts of her landscape. Five spaces with emancipatory potential to assist the academic in her professional development emerged, namely: communities of practice, academic freedom, position statements, development opportunities and a supportive environment. Rather than suggesting any generalisability in the findings, the authors argue that the significance of this study is theoretical and methodological. Complexity theory has the potential to help academic development practitioners understand the landscapes in which their academics operate, and guide appropriate development opportunities.
\end{abstract}

\section{ARTICLE HISTORY}

Received 7 July 2015

Accepted 11 July 2016

\section{KEYWORDS}

Academic development; complexity; constraints; enablements; teaching and learning

\section{Introduction}

Boud and Brew (2013) highlight the complex nature of the modern academy and the consequent increasing demands on university academics. The current knowledge-based economy has led to a massification of higher education (Enders, de Boer, \& Weyer, 2013; Ferlie, Musselin, \& Andresani, 2009; Trautwein, Nückles, \& Merkt, 2015), with governments holding universities accountable for the appropriateness of higher education outputs (Enders et al., 2013; Naidoo, 2008) and university managements transferring this accountability to academics (Knight \& Yorke, 2003). Greater levels of development of and support for academics are therefore required, particularly with regard to teaching competence (Ginns, Kitay, \& Prosser, 2010; Malcolm \& Zukas, 2001; Trautwein et al., 2015). A growing body of literature focuses on mechanisms to support university academics. Yet few studies (McPherson, Budge, \& Lemon, 2015) examine the role of introspection and reflection in how academics understand their learning environment and the role of academic staff developers in this process.

The purpose of the paper is to offer complexity theory as a mechanism for stimulating introspection and reflection, for facilitating collaboration between academics and

CONTACT Natalie Gordon ngordon@uwc.ac.za Department of Oral Hygiene, Faculty of Dentistry, University of the Western Cape, Tygerberg Campus, Bellville, Cape Town 7505, South Africa

${ }^{\dagger}$ Deceased (1961-2015).

(c) 2016 HERDSA 
academic development (AD) practitioners, and for identifying empowering opportunities within academics' landscapes.

\section{Teaching in higher education}

International emphasis on widening participation, throughput, and lecturer accountability resulted in greater scrutiny of what constitutes good teaching, the contribution of reflective practice, how academics might be assisted to develop teaching competence, and the role of the $\mathrm{AD}$ practitioner.

\section{Good teaching}

Research on good teaching, studies of good teachers, their opinions and practices, taxonomies of teaching practices, inventories of teaching conceptions, and meta-summaries is well documented (Duarte, 2013; Kane, Sandretto, \& Heath, 2004; Kember, 2009; Kember \& McNaught, 2007; Trigwell \& Prosser, 2003). Yet there is no widely accepted definition of quality teaching (Kane et al., 2004; McLean, 2001; Trigwell, 2001).

Key principles highlighted in the literature provide a working definition for this study (Duarte, 2013). Good teaching is characterised by teacher enthusiasm and passion; is learner-focused; is experientially based, participative and designed to develop critical thinking, reflection and problem-solving skills; helps students to shift their conceptual understanding; is premised on a soundly designed, relevant curriculum that aligns outcomes, teaching and learning strategies, and assessment; develop student competence through constructive feedback and involves on-going teacher reflection.

\section{Reflective practice}

Rogers (2001) identifies four characteristics of reflective practice, namely: active engagement of the individual; triggered by an experience perceived to be unusual or perplexing; involves examining personal responses, beliefs, and premises related to the experience; and results in integration of insight into existing understandings. Self-reflection is potentially introspective or ego-centric and may have an unchallenged authority, which is self-limiting (MacLaren, 2005), as the reflector is using existing beliefs to make an interpretation while not attending to underpinning assumptions (Kreber, 2004). A colleague acting as a critical friend to challenge and question may militate against this shortcoming (MacLaren, 2005).

\section{Academic staff development}

Factors that influences the uptake of professional development opportunities and the role of AD practitioners in this regard is well documented (Crawford, 2010; Kahn, 2009; Lynch, Sheard, Carbone, \& Collins, 2005; MacLaren, 2005; McPherson et al., 2015; Quinn, 2012; Smyth, 2003; Trowler \& Cooper, 2002). Studies on evidence for change of practice, and formal and informal mechanisms triggering that change, include opportunities for metacognition, conversation with peers and significant networks, and engagement with 
teaching courses (Kahn, 2009; Kreber, Castleden, Erfani, \& Wright, 2005; MacLaren, 2005; McPherson et al., 2015; Roxa \& Martensson, 2009; Trautwein et al., 2015).

The AD practitioner who does not adequately reflect on their fundamental beliefs underpinning staff development could suggest ill-advised changes in academics' practices (Smyth, 2003). Similarly, promoting changes in teaching practice regardless of teachers' implicit conceptions of good teaching, could cause unexpected outcomes such as consolidation of or return to hegemonic practices (Smyth, 2003).

\section{Methodology}

\section{Impetus for the study}

This paper is located within a broader South African national study of enablements and constraints to university teaching. As a researcher within this broader project, I was particularly struck by one interview, motivating for this study. This paper is thus lensed through the first-person voice of an $\mathrm{AD}$ practitioner.

The interviewee concerned was passionate about teaching, and experienced a strong sense of agency in actualising what she understood as the nexus between academic freedom and academic responsibility. She also signalled 'logistical issues' - aspects of university teaching and learning beyond her control and yet impinging on her ability to do her job well. I was struck by just how messy it was to be an academic with a passion for teaching (Jones, 2011).

To understand the lived reality of an academic, and the enablements and constraints which supported and clouded this role, it was necessary to map how various factors were positioned in relation to each other. Complexity theory allowed such a mapping.

\section{Complexity theory}

Complexity highlights reality as a complex open system constituted by the sum of and relationship between its parts (Cilliers, 1998). Objects, which in the study context might include curriculum, exit outcomes of accrediting professional bodies, students, lecturers and teaching space are seen as more significant than merely constituting a context (Fenwick, Edwards, \& Sawchuk, 2011; Zürcher, 2015). Rather, they are understood as continuously acting upon each other, resulting in associated knowledge being produced, distributed, obscured and denied (Fenwick et al., 2011).

Systems embody possibilities which exceed the sum of their parts and which emerge at a systems level as a whole (McMurtry, 2006). At the point of emergence, systems are unstable and there is generative potential (Clarke \& Collins, 2007) for transformation or empowerment (Fenwick et al., 2011).

Complexity is intended to study the dynamism of systems and the way in which emergences offer potential for transformation (Fenwick et al., 2011). The intention of the study is not to map dynamism. Rather it is to take a snapshot of a particular system at a point in time to identify its component parts and their inter-relationships. The analytical tools of complexity allow this examination in ways not possible with theories which privilege the linear (McMurtry, 2006). 
Similarly, my intention falls short of transformation. My purpose was to work with an academic in the identification of those emergences which had the potential to assist her personal professional development, and hence to empower her, as an academic. I therefore used the analytic tools of complexity theory, rather than its philosophical underpinnings. However, I did stay true to its emancipatory potential (Alhadeff-Jones, 2008).

Complexity argues the particularity of each system generates an explanation which is local in time and place (Alhadeff-Jones, 2013; Byrne, 2005; McMurtry, 2006). I wanted to see how mapping the teaching reality of Shirley, the research informant, would allow me to understand the component parts of the system within which she as an example of a passionate teaching academic understood, enacted and developed herself as a teacher. Fenwick and colleagues (2011, p. 177) suggest that socio-materialism encourages 'fine-grained ethnographic tracings' - an ideal perspective, for explicating meanings, which can be extrapolated from a single account. The methodology for this study is therefore a case study. I do not expect to make generalisations from the findings (Byrne, 2005; McMurtry, 2006).

\section{The data}

A standardised interview protocol, with semi-structured questions, was used for the interview. The audio-recording was transcribed for Shirley to comment.

At this point, I approached Shirley suggesting collaboration on the interpretation of her interview data. The data for this paper was thus limited to the initial interview and subsequent conversations of clarification which provided some measure of triangulation. The research subject could confirm, negate, or renegotiate the researcher's data interpretation. This limited data, a consequence of its collection as part of a larger study, is a shortcoming.

It was from the research subject's perspective and interpretation that I intended to assist her to recognise emergences, which she would find empowering, in her development as a teacher. The limited data, while militating perhaps against a more nuanced picture of the research subject's lived experience, still had the ability to provide what was needed to map her landscape. Slade (2013) similarly made use of only interviews, both focus and individual, in a complexity study of rural Scottish police officers.

\section{The collaboration}

I did an initial thematic analysis of the interview, identifying aspects which constituted the system. Shirley and I then consolidated a shared understanding of complexity and negotiated how we might use it to organise and interpret the data; then constructed a shared interpretation of the data. Thereafter I created a concept map, using the C-map tool (Novak \& Canas, 2006), to map aspects which emerged from the interview and to signal their inter-relationships. Showing these connections allowed a foregrounding of the non-linearity of the relationships between aspects. The result was a 'messy' (Fenwick et al., 2011, p. vii) concept map with connections between apparently disparate things, with some relationships unidirectional and others reciprocal. Shirley and I then discussed the concept map and whether it adequately represented the interview data (Figure 1). 


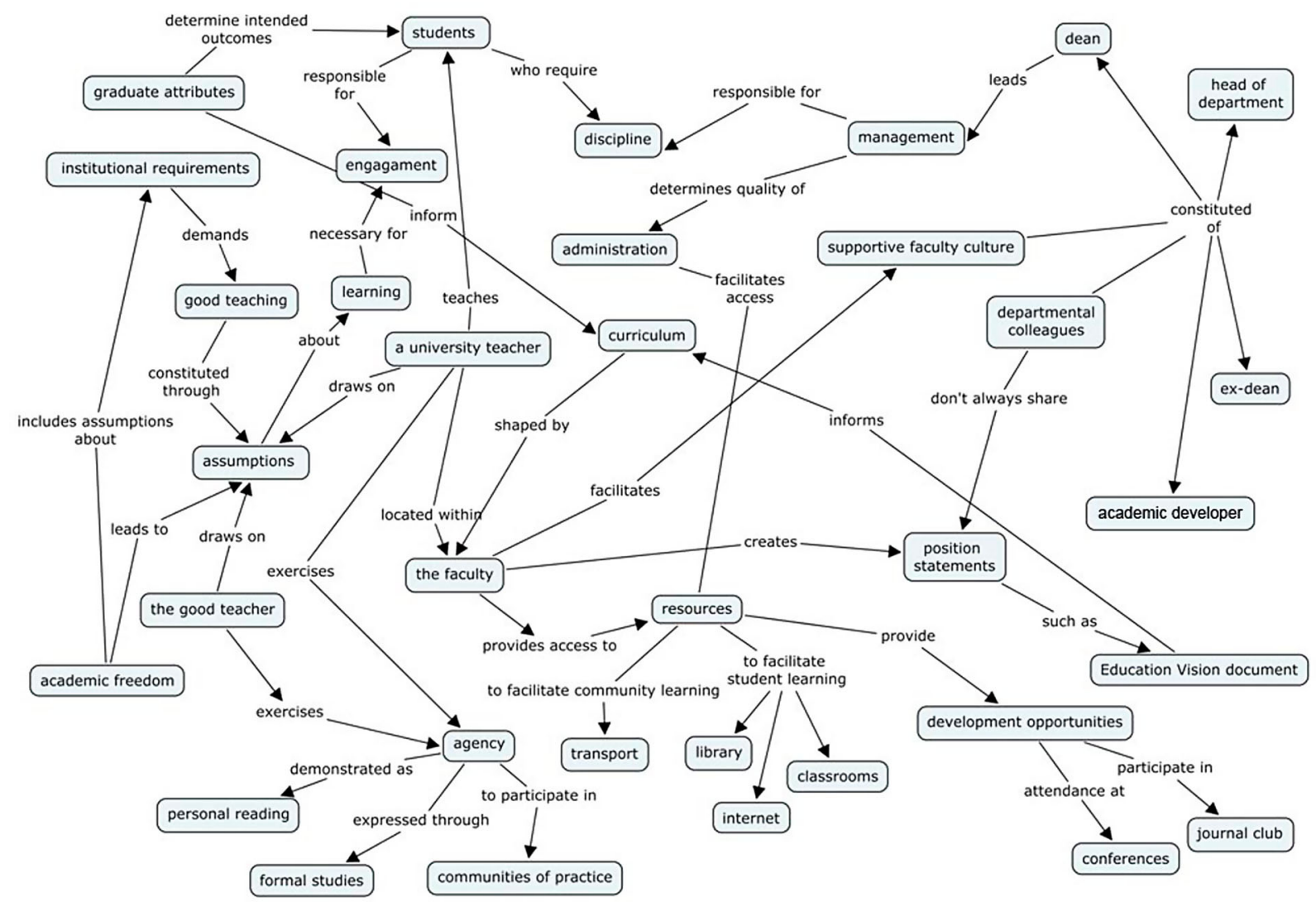

Figure 1. Complexity map of an account of teaching and professional development in higher education. 
For Shirley, participation in the mapping of her landscape facilitated some 'objectification' of her experience (McTaggart, 1991, p. 178). In an e-mail commenting on the process, she highlighted that the complexity map helped her to see herself as a part of a system,

the more the teacher role is integrated into the system, the teacher does not see herself as a teacher who has the most critical role in teaching students and developing professionals but rather the teacher is playing a role in the education process where there are other role-players who have equal value.

Shirley commented that the distancing process assisted her in recognising spaces or emergences in her landscape with the potential to be harnessed for her professional development. At this point, we did an initial identification of these emergences.

\section{An account of teaching and professional development in higher education}

The discussion below outlines Shirley's account of teaching and professional development in higher education. From this account, the component parts mapped in Figure 1 were identified.

\section{Being a university teacher}

Shirley identified the teacher role as 'teaching things so that students can understand'. She clearly found this role satisfying, 'I enjoy teaching.' Her perception of academic freedom contributed to her enjoyment, 'I can decide how I'm going to teach. If things don't work, I can change it.'

However, Shirley believed that academic freedom carries obligations that relate to quality teaching, 'We have so much freedom that I think with it comes responsibility.' She outlined the responsibility, 'The University wants lecturers who are adequately educated in terms of what we need to do.' Academic freedom was, therefore, the opportunity to exercise her obligation to teach for effective learning and with a specific purpose. Reflection was central to exercising academic freedom in a responsible way, 'I reflect on the meaning of it.'

Shirley also believed that students' motivation is an integral part of learning, 'Things I've read recently - that there must be some motivation from the student's part to learn and if that is not there, it's difficult to teach.' However, she believed that teachers had a responsibility to understand students' learning needs, 'Understanding the student profile and how I can support them.'

For Shirley, particular resources were necessary for effective teaching, 'Our resources are reasonable in terms of classrooms, we've got access to a library, internet.' She highlighted how funds available for student transport made service-learning possible, 'Community service - there's never an issue about transport.' Further, she positioned the Education Vision document for the professional programme on which she taught as a resource for shaping best practice, 'We say the curriculum is integrated, it's studentcentred. So, when I look at what I do, I ask, "Is it really integrated?"' The Education Vision document, she argued, also had the potential to align teaching across the professional programme to provide a better learning opportunity for students. 


\section{Becoming a university teacher}

Shirley assumed that the academic needed to be adequately prepared for the role as teacher, 'I think you should do an accredited course. I did. I thought, I'm not equipped for what I was doing.' She positioned professional development opportunities available to her as significant enablements to her development and performance, 'I think enablement is the availability of training for growth and development.' These opportunities were both contextual, such as the culture in her department and faculty; and actual, such as the presence of an $\mathrm{AD}$ practitioner within the faculty, conference attendance, workshops and the faculty Journal Club. Shirley described the affordance of the Journal Club, 'an opportunity to develop because when I started presenting there, you are put on the spot'. She highlighted how, in taking up professional development opportunities, she had become a resource for others. She positioned this as a further opportunity, 'I became a resource and for me that's an opportunity.'

Shirley highlighted support for her personal development by various role players within her faculty, 'There's a supportive environment in terms of wanting us to develop.' She described specifically the support of an ex-Dean, 'The confidence in me by the Dean. I was sent to an (international) education conference - for me an opportunity to be exposed.' The supportive environment also included the availability of the AD practitioner, 'I get good feedback from you.' Shirley emphasised the support of her head of department, 'The head of department has a strong sense of development for the department.' Shirley argued that the supportive environment was constituted through a particular culture within the faculty, 'if you need help people help easily and generously'.

Because of her interpretation of academic freedom, Shirley assumed that personal development in teaching came with associated obligations, 'The University has invested in you, spent time on you - what have you produced?' She was annoyed by colleagues who did not use development opportunities to improve their practice, 'Sometimes I see people going on every course there is. I would like to say, Why don't you consolidate them so that you do things right.' She highlighted how she used what she learnt to improve her own teaching:

The workshop at the conference was about oral exams. I used it for modules that I co-ordinate. We looked at orals differently. We would have a structured oral and not the kind of asking people unjust questions. So that changed in terms of opportunity.

For Shirley, however, professional learning was more than attendance. It required effort, 'Sometimes we think this course is going to do it for you, but you actually have to go read afterwards. There's no shortcut.'

Shirley highlighted the role informal networks played in her development, 'Community collaboration comes out of specific things that we are interested in. Communities form. Once you get into those communities, you learn.' Because she positioned personal development as a teacher as an pre-requisite for effective university teaching, and as a requirement of her university, Shirley was implicitly dismissive of the frequently used argument in academia of insufficient time to add this kind of development to academics' workload. She argued that self-development activities created communities of practice which in themselves were time-efficient ways of gaining personal development, 'Our (University's) alignment (workshop) created spin-offs in terms of people I started working with. They 
create networks. We're all busy but we could all do bits and pieces and we could work together.'

\section{There are lots of logistical issues}

Shirley identified constraints as a teacher as 'logistical issues'. These related to perceptions of shared vision, management practices, and role clarification. Shirley perceived that not all colleagues shared the vision for teaching and learning negotiated for their professional programme. Managing initiatives alone, Shirley argued, had a knock-on effect on quality learning, 'The amount of learning isn't always worth the amount of effort that it takes to set up that project.'

Perceptions of management practices and associated role clarification were expressed by Shirley as constraints. She argued that student discipline was not the teacher's responsibility:

We sometimes take responsibilities that should not be ours. If there are problems with students, I think its management's problem. It really is a constraint because we're kept busy with things we shouldn't be kept busy with. If faculty can take on those issues, we can focus on our teaching.

\section{Identifying potentially empowering emergences}

Five spaces with emancipatory potential to assist Shirley in her professional development emerged, namely: communities of practice, academic freedom, position statements, development opportunities and a supportive environment. These were aspects of the landscape which were not already rigidly defined in her context. It therefore had the potential to be harnessed by Shirley, for her own interpretation and use, to support her professional learning in improving her practice as a teacher. In this process, she had the potential to include others into her practices and empowerment.

\section{Communities of practice}

Shirley noted the potential of communities of practice to provide opportunities for participants to learn. Networks, especially informal, ad hoc ones in the academics' discipline can result in empowering relationships that shape practice (Crawford, 2010; Roxa \& Martensson, 2009). The most effective of these networks are small, with members coming together naturally to discuss and share good practice (Crawford, 2010). In this way, they have the potential to disrupt taken-for-granted ways of being and doing (Brown \& Duguid, 1991).

As they were currently positioned on the landscape, the communities within the research site were ad hoc groupings, growing informally out of short term projects, 'individuals within the Faculty work on projects together' or are loose connections such as constituted through Journal Club attendance, 'I go to Journal Club - so these communities form.' However, Shirley's perception was that since not everyone participated in such communities, conversations about curriculum were limited, or even impossible, because there was not shared insight or language, 'if you're doing something, do you recognise that there are different students, that there are different needs of the students, and the learning opportunities should be different for the students? 
Wenger, McDermott, and Snyder (2002) suggest mechanisms which community participants, such as Shirley, might harness to empower and cultivate communities of practice. These include keeping the community engagement 'alive' by inviting interaction between participants and inviting the participation of new individuals - strategies which Shirley was already using, 'and I said, "Why don't you come?"'. Focused activities such as collaborative research and journal club-type activities, in which Shirley already participated, make a contribution in this regard, and provide opportunities for her to create and nurture communities of practice both for herself and her colleagues.

The AD practitioner may engage as a potentially powerful peripheral member to initiate, support and develop colleagues through co-ordination of more formal communities such as Journal Clubs, assist with development of research proposals, or simply act as a conversant.

\section{Academic freedom}

Shirley identified academic freedom as providing space for the development of responsive and innovative teaching and learning activities. Perceptions of academic autonomy play a significant role in academics' uptake of development opportunities (Crawford, 2010; McKenna \& Boughey, 2014). Academic autonomy is premised on assumptions about academic freedom. Academic freedom is not an uncontested concept, mostly because it is not clearly defined (Karran, 2009) and because of inroads from managerialism in higher education (Altbach, 2001; Enders et al., 2013). Foundational principles of academic freedom, and those consolidated as Humboldtian, is associated with both teaching and learning freedom to research and teach within the teacher's field of expertise, without external control, and implicitly freedom of the student to learn (Altbach, 2001; Karran, 2009; Metz, 2010). Academic freedom has been associated with freedom of the academic to choose disciplinary concepts, sources and associated teaching strategies and learning activities (Karran, 2009; Rostan, 2010). Academic freedom, when supported and theorised through 'best practice', has the potential to create exemplars of innovative and effective teaching and learning.

While Shirley clearly held a Humboldtian understanding of academic freedom, she perceived that this interpretation was not universally shared across her faculty, 'I'm not always sure that we take responsibility for what we do - I think we're lacking some commitment.' This lack, she argued, was manifest in colleagues not electing to skill themselves in the competencies which would allow them to better address students' needs. Shirley implied that, as a consequence, student learning was compromised because colleagues did not always share a common language.

There may be little that an academic can do to address perceived shortcomings at the structural level. Shirley exercised her academic freedom through selection, and teaching, of her disciplinary content, 'we have the sort of freedom to - maybe not experiment - but to try different things ... I will find ways to teach in order for them to learn'; and by taking up opportunities to develop her competence as a teacher, 'I had the foundation by doing that course.' It is arguable that identifying academic freedom as an emancipatory space for the purposes of this study is short-sighted, given Shirley's perception about constraints out of her control. However, it was through the process of mapping her landscape, and discussing the emerging spaces with her, that Shirley came to realise the potential of academic 
freedom as she interpreted it to empower herself, as an academic, and to support her professional learning. Academic freedom, with its emphasis on choice, had the potential to allow Shirley to imagine how she might achieve the ways of being and becoming the academic that she desired.

The role of the $\mathrm{AD}$ practitioner might be to advise management to harness academic freedom in ways which, through accountability, ensured transferable professional learning - similar to ways Shirley had suggested, 'Some sort of monitoring - it can be at a very informal departmental level to say, "You've done this. What change have you made?"' Managerialism inherent in this suggestion is often associated with infringement of academic freedom. In this regard, ADs may need to construct developmental opportunities for academics; with part of the underpinning discourse being a reiteration of the Humboldtian notion that academic freedom includes the freedom of students to have the best possible learning experience. This implies access to enabling teaching.

\section{Position statements}

Policy or position statements are intended to guide how decisions are made and how work is done within an organisation (Dyson, 1999). They have the potential, when created collaboratively and authentically, to inform practice and contribute to the development of communities of practice and a shared language (Innes \& Booher, 2003). Collaborative development can ensure buy-in, and allows people who are going to use the statement to decide the content and how its principles should guide practice (Innes \& Booher, 2003). Aspects of managerialist quality assurance, such as formalised student and head of department evaluation, can potentially improve the calibre of teaching, but only when the teacher already has a personal commitment to quality teaching and learning (Karran, 2009).

Shirley perceived that some colleagues had merely gone through the motions while with others the Vision Document, informing the programme, served as a shared focal point for discussion of issues related to teaching and learning. She saw the document as dynamic, flexible enough to accommodate new insights into teaching and learning, 'If this is what our vision was, maybe it's changed. And if it's changed, let's change it.'

Collaboratively designed position statements can potentially support shared conversations about practice and act as foci for communities of practice. This study, supported by the literature, suggests that such a quality assurance mechanism can only emerge as a space for teacher empowerment if there is a sense of ownership of the document. Such an emergence might be used to empower academics in different ways. Shirley benchmarked her practice on markers in the Vision Document, on the premise that the process which had developed the document ensured best practice. Both the development of such a document and the process of ensuring that it remains relevant are within the ambit of academics. The AD might provide expertise to guide academics to create a document which can be owned by all.

\section{Development opportunities}

For Shirley, development opportunities provided the mechanisms for her to capacitate herself and to share her learning. Targeted professional development has the potential 
to create individuals with expertise to become champions within a faculty (Anderson, Varnhagen, \& Campbell, 1998; Wilson, 2004). Anderson and colleauges (1998) suggest that 'experts' from 'within the ranks' are effective channels for the dissemination of innovation, presumably because academics perceive them as 'one of us', a status not always attributed to ADs.

\section{Personal development}

Shirley enumerated a diversity of development opportunities that she had taken up, including post-graduate study, attendance at staff development activities, conferences attendances and engaging in research into teaching and learning. For each activity, she explained how she had used what she had learnt. Clearly, because of her understanding of academic freedom as a balance of rights and corresponding responsibilities, she assumed that she engaged in development to support her students' learning.

Accessing development opportunities is clearly an empowering space for academics. They may, however, need support in gaining the confidence to engage in such opportunities. The role of the AD thus becomes clear - to provide support, to facilitate opportunities for learning, and to advocate for institutional and regional collaborative activities.

\section{Helping to develop others}

Shirley believed that, in capacitating herself, she had become a resource for others. She had little to say about constraints associated with this emergence. Instead she suggested that her growing expertise was valued by others, 'status isn't important but you see it when people start asking you questions'.

Champions are in a tenuous position in terms of being able to facilitate real change, since they are reliant on good will rather than any institutional authority. It is then arguable that champions have the potential to support innovation because they will have to approach the dissemination of their ideas in a democratic collaborative way. The AD has a contribution to make in facilitating the development of champions and in facilitating a supportive environment for their engagement with colleagues.

\section{Supportive environment}

Shirley highlighted the way in which a supportive environment facilitated her development as a teacher. While managerialism has a potentially negative effect on academic freedom, those in leadership positions at universities can play a significant and positive role in nurturing academic freedom. A supportive environment can be nurtured and developed by those in leadership positions (Morrison, Brown, \& Smit, 2006). Shirley enumerated, in her interview, numerous management practices which she experienced as empowering - a supportive Dean and Head of Department, supportive colleagues, and the appointment of an in-house AD. The corollary is that neglecting to provide such opportunities has the potential to compromise opportunities for academics to be and become teachers.

Not all academics have access to spaces identified by Shirley, and even where they exist, not all academics choose to make use of them. One mechanism which academics might use to accelerate this emergent space is to argue the 'cost-benefit' advantage, of the development opportunities, by outlining the benefits to them as teachers and to students as 
learners. Shirley did this when she explained to her Head of Department how her attendance at a workshop would benefit students. Selling 'cost-benefit' to faculty management, in view of potential benefits of opportunities to improve teaching and learning, may also be the mandate of $\mathrm{AD}$ practitioners.

\section{Conclusion}

This paper has examined how one academic framed the enablements and constraints to her project of being and becoming an academic. Complexity allowed the teacher to see the landscape as she had described it, but also as an outsider. To some extent, complexity allowed for an unbiased scrutiny of what constituted the evidence. In this process, spaces with emancipatory potential to assist the academic in her professional development emerged.

Rather than suggesting any generalisability in the findings, the authors argue that the significance of this study is theoretical and methodological. Complexity theory has the potential to help $\mathrm{AD}$ practitioners understand the landscapes in which their academics operate and so help ADs better negotiate learning needs of academics.

\section{Disclosure statement}

No potential conflict of interest was reported by the authors.

\section{Funding}

This research is funded by the National Research Foundation (grant number 90353).

\section{References}

Alhadeff-Jones, M. (2008). Three generations of complexity theories: Nuances and ambiguities. Educational Philosophy and Theory, 40(1), 66-82.

Alhadeff-Jones, M. (2013). Complexity, methodology and method: Crafting a critical process of research. Complicity: International Journal of Complexity and Education, 10(1/2), 19-44.

Altbach, P. (2001). Academic freedom: International realities and challenges. Higher Education, 41, 205-219.

Anderson, T., Varnhagen, S., \& Campbell, K. (1998). Faculty adoption of teaching and learning technologies: Contrasting earlier adopters and mainstream faculty. The Canadian Journal of Higher Education, 28(2), 71-98.

Boud, D., \& Brew, A. (2013). Reconceptualising academic work as professional practice: Implications for academic development. International Journal for Academic Development, 18 (3), 208-221.

Brown, J., \& Duguid, P. (1991). Organizational learning and communities-of-practice: Toward a unified view of working, learning and innovation. Organization Science, 2(1), 40-57.

Byrne, D. (2005). Complexity, configuration and cases. Theory, Culture and Society, 22(5), 95-111.

Cilliers, P. (1998). Complexity and postmodernism: Understanding complex systems. London: Routledge.

Clarke, A., \& Collins, S. (2007). Complexity science and student teacher supervision. Teaching and Teacher Education, 23(2), 160-172.

Crawford, K. (2010). Influences on academics' approaches to development: Voices from below. International Journal for Academic Development, 15(3), 189-202. 
Duarte, F. (2013). Conceptions of good teaching by good teachers: Case studies from an Australian university. Journal of University Teaching and Learning Practice, 10(1). Retrieved from http://ro. uow.edu.au/jutlp/vol10/iss1/5/

Dyson, M. (1999). How and when to write policies and procedures. Ashgrove: Australian Council for the Rehabilitation of the Disabled. Retrieved from https://www.safework.sa.gov.au/contentPages/ docs/labrWritingPolicy.pdf

Enders, J., de Boer, H., \& Weyer, E. (2013). Regulatory autonomy and performance: The reform in higher education re-visited. Higher Education, 65, 5-23.

Fenwick, T., Edwards, R., \& Sawchuk, P. (2011). Emerging approaches in educational research. Tracing the socio-material. London: Routledge.

Ferlie, E., Musselin, C., \& Andresani, L. (2009). The governance of higher education systems: A public management perspective. In C. Paradeise, E. Reale, I. Bleiklie, \& E. Ferlie (Eds.), University governance: Western European perspectives (pp. 1-19). Dordrecht: Springer.

Ginns, P., Kitay, J., \& Prosser, M. (2010). Transfer of academic staff learning in a research-intensive university. Teaching in Higher Education, 15(3), 235-246.

Innes, J., \& Booher, D. (2003). Collaborative policymaking: Governance through dialogue. In M. A. Hajer \& H. Wagenaar (Eds.), Deliberative policy analysis. Understanding governance in the network society (pp. 33-59). Cambridge: Cambridge University Press.

Jones, A. (2011). Seeing the messiness of academic practice: Exploring the work of academics through narrative. International Journal for Academic Development, 16(2), 109-118.

Kahn, P. (2009). Contexts for teaching and the exercise of agency in early-career academics: Perspectives from realist social theory. International Journal for Academic Development, 14(3), 197-207.

Kane, R., Sandretto, S., \& Heath, C. (2004). An investigation into excellent tertiary teaching: Emphasising reflective practice. Higher Education, 47, 283-310.

Karran, T. (2009). Academic freedom: In justification of a universal ideal. Studies in Higher Education, 34(3), 263-283.

Kember, D. (2009). Promoting student-centred forms of learning across an entire university. Higher Education, 58, 1-13.

Kember, D., \& McNaught, C. (2007). Enhancing university teaching: Lessons from research into award winning teachers. London: Routledge.

Knight, P., \& Yorke, M. (2003). Employability and good learning in higher education. Teaching in Higher Education, 8(1), 3-16.

Kreber, C. (2004). An analysis of two models of reflection and their implcations for educational development. International Journal for Academic Development, 9(1), 29-49.

Kreber, C., Castleden, H., Erfani, N., \& Wright, T. (2005). Self-regulated learning about university teaching: An exploratory study. Teaching in Higher Education, 10(1), 75-97.

Lynch, J., Sheard, J., Carbone, A., \& Collins, F. (2005). Individual and organisational factors influencing academics' decisions to pursue the scholarship of teaching ICT. Journal of Information Technology Education, 4. Retrieved from www.jite.org/documents/Vol4/v4p219-236Lynch56.pdf

MacLaren, I. (2005). New trends in academic staff development: Reflective journals, teaching portfolios, accreditation and professional development. In G. O’Neill., S. Moore, \& B. McMullin (Eds.), Emerging issues in the practice of university learning and teaching. Dublin: AISHE. Retrieved from http://www.aise.org/readings/2005-1/

Malcolm, J., \& Zukas, M. (2001). Bridging pedagogic gaps: Conceptual discontinuities in higher education. Teaching in Higher Education, 6(1), 33-42.

McKenna, S., \& Boughey, C. (2014). Argumentative and trustworthy scholars: The construction of academic staff at research-intensive universities. Teaching in Higher Education, 19(7), 825-834.

McLean, M. (2001). Rewarding teaching excellence. Can we measure 'excellence'? Medical Teacher, 23(1), 6-11.

McMurtry, A. (2006). Professional knowledge, complexity and interdisciplinary teams. Crossing Boundaries: An Interdisciplinary Journal, 1(2), 35-51. 
McPherson, M., Budge, K., \& Lemon, N. (2015). New practices in doing academic development: Twitter as an informal learning space. International Journal for Academic Development, 20(2), 126-136.

McTaggart, R. (1991). Principles for participatory action research. Adult Education Quarterly, 41 (3), 168-187.

Metz, T. (2010). A dilemma regarding academic freedom and public accountability in higher education. Journal of Philosophy of Education, 44(4), 529-549.

Morrison, J., Brown, C., \& Smit, E. (2006). A supportive organisational culture for project management in matrix organisations: A theoretical perspective. South African Journal of Business Management, 37(4), 39-54.

Naidoo, R. (2008). The competitive state and the mobilised market: Higher education policy reform in the United Kingdom (1980-2007). Critique Internationale, 39(2), 47-65.

Novak, J., \& Canas, A. (2006). The origins of the concept mapping tool and the continuing evolution of the tool. Information Visualization, 5, 175-184.

Quinn, L. (2012). Understanding resistance: An analysis of discourse in academic staff development. Studies in Higher Education, 37(1), 69-83.

Rogers, R. (2001). Reflection in higher education: A concept analysis. Innovative Higher Education, 26(1), 37-57.

Rostan, M. (2010). Challenges to academic freedom: Some empirical evidence. European Review, 18 (1), S71-S88.

Roxa, T., \& Martensson, K. (2009). Significant conversations and significant networks. Exploring the backstage of the teaching arena. Studies in Higher Education, 34(5), 547-559.

Slade, B. (2013). Professional learning in rural practice: A sociomaterial analysis. Journal of Workplace Learning, 25(2), 114-124.

Smyth, R. (2003). Concepts of change: Enhancing the practice of academic staff development in higher education. International Journal for Academic Development, 8(1/2), 51-60.

Trautwein, C., Nückles, M., \& Merkt, M. (2015). Complex dynamics in academics' development processes in teaching. Higher Education Research \& Development, 34(3), 641-657.

Trigwell, K. (2001). Judging university teaching. International Journal for Academic Development, 6 (1), 65-73.

Trigwell, K., \& Prosser, M. (2003). Qualitative difference in university teaching. Access and Exclusion, 2, 185-216.

Trowler, P., \& Cooper, A. (2002). Teaching and learning regimes: Implicit theories and recurrent practices in the enhancement of teaching and learning through educational development programmes. Higher Education Research \& Development, 21(3), 221-240.

Wenger, E., McDermott, R., \& Snyder, W. (2002). A guide to managing knowledge. Cultivating communities of practice. Boston, MA: Harvard Business School.

Wilson, G. (2004). Online interaction impacts on learning: Teaching the teachers to teach online. Australian Journal of Educational Technology, 20(1), 33-48.

Zürcher, R. (2015). A sociomaterial model of the teaching-learning continuum. European Journal for Research on the Education and Learning of Adults, 6(1), 73-90. 